\title{
Characterization of the role of Smu1 in nuclear localization of splicing factors in the mammalian temperature-sensitive mutant
}

\author{
Kimihiko Sugaya, Yoshie Ishihara, Keiko Sugaya, Sonoe Inoue \\ Research Center for Radiation Protection, National Institute of Radiological Sciences, Chiba, Japan \\ Email: k_sugaya@nirs.go.jp
}

Received 16 October 2012; revised 16 November 2012; accepted 24 November 2012

\begin{abstract}
A temperature-sensitive (ts) mutant of the CHO-K1 cell line, tsTM18, grows at $34^{\circ} \mathrm{C}$ but not at $39^{\circ} \mathrm{C}$. Smu1 is the gene responsible for ts defects of tsTM18 cells. Previously, we found that the Smu1 ts defect altered the localization (as indicated by enlargement of speckles) of SRSF1 (SF2/ASF) in tsTM18 cells cultured at $39^{\circ} \mathrm{C}$, suggesting a functional association between Smu1 and SRSF1. Speckles are subnuclear structures that may function as storage/assembly/ modification compartments to supply splicing factors to active transcription sites. The effect of the ts defect of Smu1 on the localization of other factors related to splicing has not been characterized yet. The mechanisms underlying the enlargement of speckles of SRSF1 remain unclear. In the present study, we found that the ts defect of Smu1 affected the nuclear localization of a splicing factor, SRSF2 (SC35), and factors involved in the exon-exon junction complex, Y14 and ALY. Reverse transcription-polymerase chain reaction (RT-PCR) analysis revealed that the ts defect of Smu1 affected alternative splicing of endogenous Clk1/ Sty and SRSF2 genes. Mammalian Clk family kinases are shown to phosphorylate serine/arginine (SR) proteins in vitro and SRSF1 in vivo. RT-PCR analysis of Clk1/Sty showed an accumulation of the truncated form lacking kinase activity in tsTM18 cells incubated at $39^{\circ} \mathrm{C}$. These data indicate that an accumulation of kinase-negative Clk1/Sty may lead to alteration of the localization of factors related to splicing resulting in the enlargement of speckles.
\end{abstract}

Keywords: Alternative Splicing; Phosphorylation; Speckle; Splicing; Temperature-Sensitive Mutation

\section{INTRODUCTION}

Splice site selection in higher eukaryotes is determined by multiple factors involving cis-acting regulatory ele- ments and their binding proteins. Serine/arginine-rich (SR) splicing factors, which also have characteristic RNAbinding domains, are necessary for an early step in the spliceosome assembly and can influence the selection of alternative splice sites [1-3]. SR proteins often bind to exonic splicing enhancers, whereas heterogeneous nuclear ribonucleoproteins typically bind to exonic splicing silencers. During splicing, factors required for translation, quality control, and export are recruited to the mRNA. These proteins are deposited on 20 - 24 nucleotides upstream of the mRNA exon-exon junction and are referred to as the exon-exon junction complex (EJC) [4,5].

"Speckles" are subnuclear structures that are visualized by immunofluorescence microscopy, typically using antibodies raised against factors essential for splicing [6]. Usually 25 - 50 speckles, which range in size from one to several micrometers in diameter, are observed per interphase mammalian nucleus. It is suggested that speckles are dynamic structures and may function as storage/assembly/modification compartments to supply splicing factors to active transcription sites. When transcription or pre-mRNA splicing is inhibited, splicing factors accumulate predominantly in enlarged, rounded speckles [6].

A temperature-sensitive (ts) mutant of the CHO-K1 cell line, tsTM18, grows at $34^{\circ} \mathrm{C}$ but not at $39^{\circ} \mathrm{C}$ [7]. Smu1 is the gene responsible for ts defects of tsTM18 cells [8]. In our previous study, we found that introducetion of a hybrid gene encoding Smu1 tagged with green fluorescent protein allowed tsTM18 cells to grow at $39^{\circ} \mathrm{C}$, resulting in co-localization with SRSF1 [9]. SRSF1 (SF2/ASF) is a member of the SR splicing group of factors $[10,11]$ and is considered to be involved in the integrity of genome maintenance [12]. We also found that the ts defect of Smu1 appeared to alter the localization (indicated by enlargement of speckles) of SRSF1 in tsTM18 cells cultured at $39^{\circ} \mathrm{C}$, suggesting a functional association between Smu1 and SRSF1 [9]. Inhibition of transcription often results in changes in the size, shape, and number of speckles [6]. However, the enlargement of 
speckles by the ts defect of Smu1 was independent of the activity of transcription [9]. We also revealed that incubation at $39^{\circ} \mathrm{C}$ resulted in a significant decrease in Smu1 in tsTM18 cells [9]. Judging from our previous results, Smu1 may function in the proper localization of SRSF1 at the sites of mRNA processing. However, the mechanisms underlying the enlargement of speckles of SRSF1 remain unclear. In the present study, we found that the accumulation of transcript that encodes kinase-negative form of Clk1. We also identified the altered localization in a Smu1-dependent manner of proteins involved in mRNA processing, SRSF2, ALY, and Y14.

\section{MATERIALS AND METHODS}

\subsection{Cells}

The Chinese hamster cell line, CHO-K1, and its ts-mutant cell, tsTM18, were grown in Ham's F-12 medium (Sigma-Aldrich, St. Louis, MO, USA) containing 10\% fetal calf serum, $2 \mathrm{mM}$ L-glutamine, and antibiotics (Gibco/Invitrogen, Carlsbad, CA, USA).

\subsection{Indirect Immunolabeling and Microscopy}

Procedures for the indirect immunolabeling and microscopy of immunolabeled cells have been described previously [13]. Primary antibodies used in this study were mouse anti-SRSF2 (clone SC35; 1:500 immunofluorescence [IF]; PharMingen/BD, San Diego, CA, USA), antiALY (clone 11G5; 1:200 IF; Santa Cruz Biotechnology, Santa Cruz, CA, USA), and anti-Y14 (clone 4C4; 1:200 IF; Santa Cruz Biotechnology). The size and number of fluorescently labeled speckles per nucleus was determined with ImageJ 1.42q (http://rsb.info.nih.gov/ij/; http://www.macbiophotonics.ca/imagej/). This analysis was performed by applying a threshold intensity limit to produce binary images that could be measured and counted.

\subsection{RT-PCR}

Procedures for RT-PCR have been described previously [14]. RT-PCR of the hamster Clk1/Sty, SRSF2, Bcl-X, and $C D 44$ genes was carried out with the following primer pairs: Clk1/Sty,

5'-GCATAGTAGCAAGTCCTCTG-3' and

5'-TACTGCTACACGTCTACCTC-3'; $S R S F 2$,

5'-CAAGTCTCCAGAAGAAGAGG-3' and

5'-GCATTACTCAACTGCTACAC-3'; $B c l-X$,

5'-ATGTCTCAGAGCAACCGGGA-3' and

5'-TCACTTCCGACTGAAGAGTG-3'; CD44,

5'-CTATTGTCAACCGTGATGGTAC-3' and

5'-GCCAGGAGAGATGCCAAGATG-3'. Band

intensities were measured with ImageJ 1.34S

(http://rsbweb.nih.gov/ij/docs/menus/analyze.html).

\section{RESULTS}

\subsection{Temperature-Sensitive Defect of Smu1 Alters the Nuclear Localization of Splicing Factors}

The effect of the ts defect of Smu1 on the localization of other factors related to splicing has not been characterized yet. We examined the localization of proteins related to splicing with antibodies raised against them. SRSF2 (SC35) is involved in pre-mRNA splicing and is found in speckles [15]. "Splicing speckles” are major nuclear domains rich in components of the splicing machinery [6]. We found enlarged signals of anti-SRSF2 in the tsTM18 cells at $39^{\circ} \mathrm{C}$ (Figure 1(a)). However, changes in speckles containing SRSF2 caused by incubation at $39^{\circ} \mathrm{C}$ appeared to be less significant than those in speckles containing SRSF1. According to our previous study [9], the average size of enlarged speckles of SRSF1 was larger than $0.3 \mu^{2}$, but that of SRSF2 was approximately 0.1 $\mu \mathrm{m}^{2}$ (Figure 1(b)).

We also obtained similar results to those of antiSRSF1 with two other antibodies raised against components of the EJC, anti-ALY and anti-Y14 (Figure 1(a)). Studies addressing the structure of the EJC/RNA complex suggest that Y14 and ALY are involved in the EJC as a component of a stable tetrameric inner core and as one of the outer shell proteins, respectively [16-18]. In both $\mathrm{CHO}-\mathrm{K} 1$ and tsTM18 cells grown at $34^{\circ} \mathrm{C}$, anti-Y14 yielded many small bright foci in discrete nucleoplasmic sites but few in the nucleoli or the cytoplasm. At the same temperature, anti-ALY yielded more diffuse nuclear staining than did anti-Y14 and some diffuse staining in the cytoplasm (Figure 1(a)). In tsTM18 cells, incubation at $39^{\circ} \mathrm{C}$ resulted in the greater accumulation of ALY or Y-14 than at $34^{\circ} \mathrm{C}$, and both antibodies showed obviously enlarged nuclear speckles after 8 hours of incubation. Growth at $39^{\circ} \mathrm{C}$ also induced more cytoplasmic labeling of ALY (Figure 1(a)).

\subsection{Temperature-Sensitive Defect of Smu1 Affects Alternative Splicing}

A number of studies have reported that Clk kinases can modulate the localization and function of SR proteins in the nucleus [19-21]. It is possible that Clk family kinases are key regulators of SR protein function, which in turn regulate alternative splicing, by phosphorylating SR proteins. This phosphorylation also affects the subcellular localization [22] and the stability of a particular SR protein [23]. We therefore analyzed the localization of Clk1 kinase in tsTM18 cells incubated at $39^{\circ} \mathrm{C}$ by indirect immunostaining. However, there was no temperature effect on the distribution of Clk1 kinase in tsTM18 cells (data not shown). Then, we analyzed changes in the splicing profiles of $C l k 1 / S t y, S R S F 2, B c l-X$, and $C D 44$ 
(a)

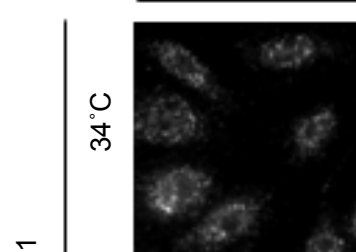

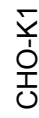

○
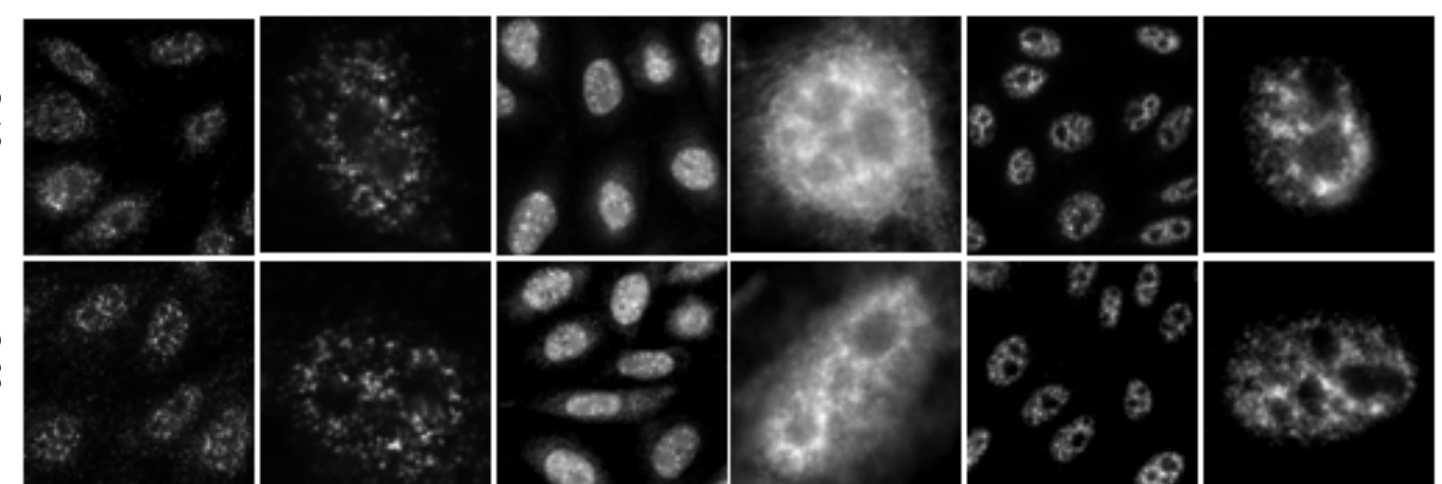

(1)
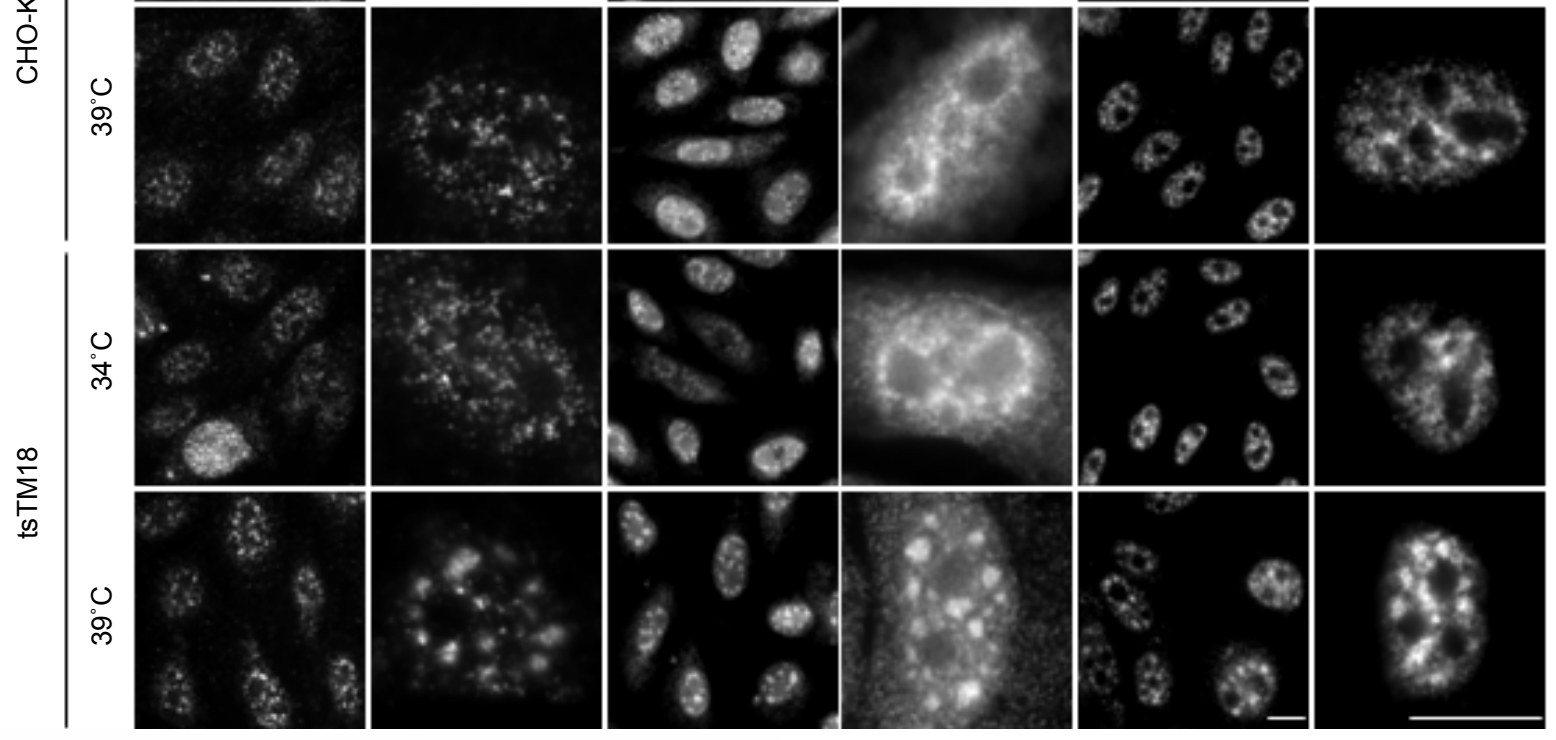

(1)
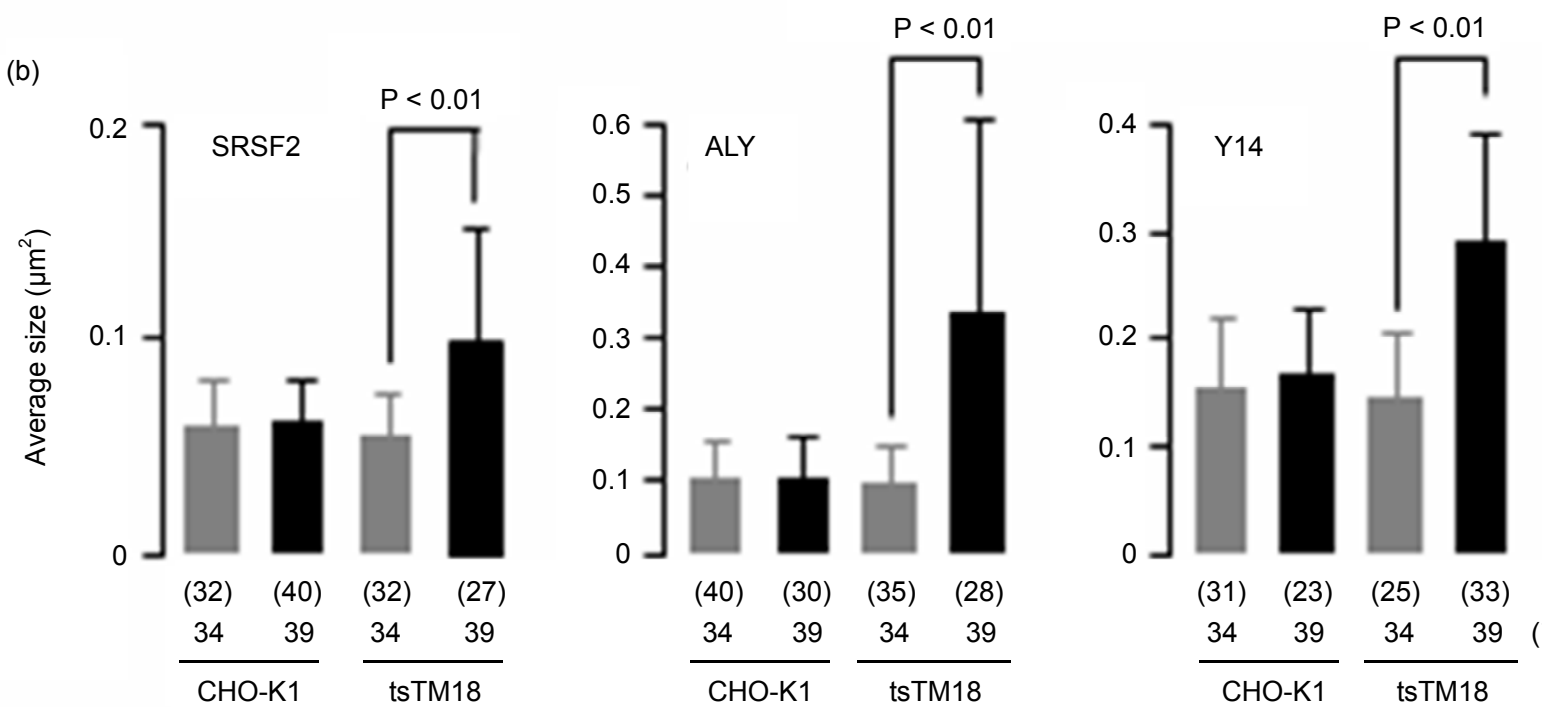

Figure 1. Temperature-sensitive (ts) defect of Smu1 alters the nuclear localization of SRSF2, ALY, and Y14. (a) Wild-type CHO-K1 or ts mutant tsTM18 cells were grown at $34^{\circ} \mathrm{C}$ or incubated at $39^{\circ} \mathrm{C}$ for 8 hours and fixed. Next, SRSF2, ALY, and Y14 were indirectly immunolabeled with Alexa 568. Scale bar, $10 \mu \mathrm{m}$. Higher magnification views are shown right of each low-power image. The distributions of splicing factors in wild-type and mutant cells are similar at $34^{\circ} \mathrm{C}$, but growth at $39^{\circ} \mathrm{C}$ induced some larger nuclear bodies in mutant cells. (b) Quantitative analyses of speckles for SRSF2, ALY, and Y14. Pixel size of speckles in the equatorial section of each nucleus, such as those shown in the images (a), were analyzed and represented as the average size with standard deviation in each nucleus. $P$ values were calculated by Student's $t$-test. Numbers of nuclei measured are shown in parentheses. Under- and overestimates are included in the results of ALY because cells contained significant labeling in cytoplasm. In mutant cells, incubation at $39^{\circ} \mathrm{C}$ resulted in accumulation of SRSF2, ALY, and Y14.

because alteration of the splicing patterns of these genes has been reported [24,25]. Reverse transcription-poly- merase chain reaction (RT-PCR) revealed that tsTM18 cells showed changes in splicing profiles of both the 
Clk1/Sty and $S R S F 2$ genes during the culture at $39^{\circ} \mathrm{C}$ but no change in the splicing profiles of the $B c l-X$ and $C D 44$ genes (Figure 2).

Mouse Clk1/Sty isoforms are translated from two alternatively spliced transcripts encoding either a fulllength catalytically active protein, 274 nucleotide (nt), Clk1/Sty or a truncated protein lacking the catalytic domain, 183 nt, Clk1/StyT [19]. In CHO-K1 cells, PCR product corresponding to the short form corresponding with Clk1/StyT was observed in addition to the long form corresponding with Clk1/Sty, showing good conservation of gene structure (Figure 2(a)). It is reported that Clk1/Sty regulates splicing of its own pre-mRNA according to its kinase activity; increased expression of the catalytically active Clk1/Sty influences splicing to generate the splicing variant that lacks exon 2 and thus encodes the kinase-negative Clk1/StyT [19]. We assessed the effect of the ts defect of Smu1 on the kinase activitymediated exon skipping of Clk1/Sty pre-mRNA by RTPCR. Incubation at $39^{\circ} \mathrm{C}$ induced exon skipping and increased the levels of the truncated form (183 nt) in tsTM18 cells, as shown in Figure 2(b).

A subtle change of the SRSF2 splicing profile was also observed (Figure 2(b)). In CHO-K1 cells, PCR products corresponding to the long-form (668 nt) and the short-form (274 and $170 \mathrm{nt}$ ) transcripts for SRSF2 were detected. Incubation at $39^{\circ} \mathrm{C}$ increased the band intensity of the $274 \mathrm{nt}$ in $\mathrm{CHO}-\mathrm{K} 1$ cells and decreased that of the
$274 \mathrm{nt}$ in tsTM18 cells. Variation of splicing isoforms of SRSF2 detected by RT-PCR corresponds to the alteration of the 3' untranslated region, which is responsible for SRSF2 mRNA destabilization [26]. We have not obtained any results showing significant changes in the amount of SRSF2 protein in tsTM18 cells cultured at $39^{\circ} \mathrm{C}$. Further analysis is needed to clarify the physiological role of alternative splicing of $S R S F 2$ with the ts defect of Smu1 in tsTM18 cells at $39^{\circ} \mathrm{C}$.

\section{DISCUSSION}

We found altered localization in a Smu1-dependent manner of proteins involved in mRNA processing, SRSF2, ALY, and Y14 (Figure 1). These proteins appeared as enlarged speckles in tsTM18 cells at the nonpermissive temperature, although morphological and quantitative changes in the speckles appeared to be less significant in comparison with those of SRSF1 [9]. The involvement of two EJC proteins, ALY and Y14, in the altered localization may be consistent with a role of mRNA surveillance. The EJC is a multi-protein complex that is involved in mRNA export, cytoplasmic localization, and nonsensemediated mRNA decay. Recently, in vivo analysis with different fluorescence fluctuation microscopy techniques revealed that ALY and Y14 showed a reduction in their nuclear mobility when they complexed with RNA and interacted with nuclear speckles [27]. Our immunofluorescence analysis of ALY and Y14 may suggest that ac-

(a)

Clk1

SRSF2 (SC35)
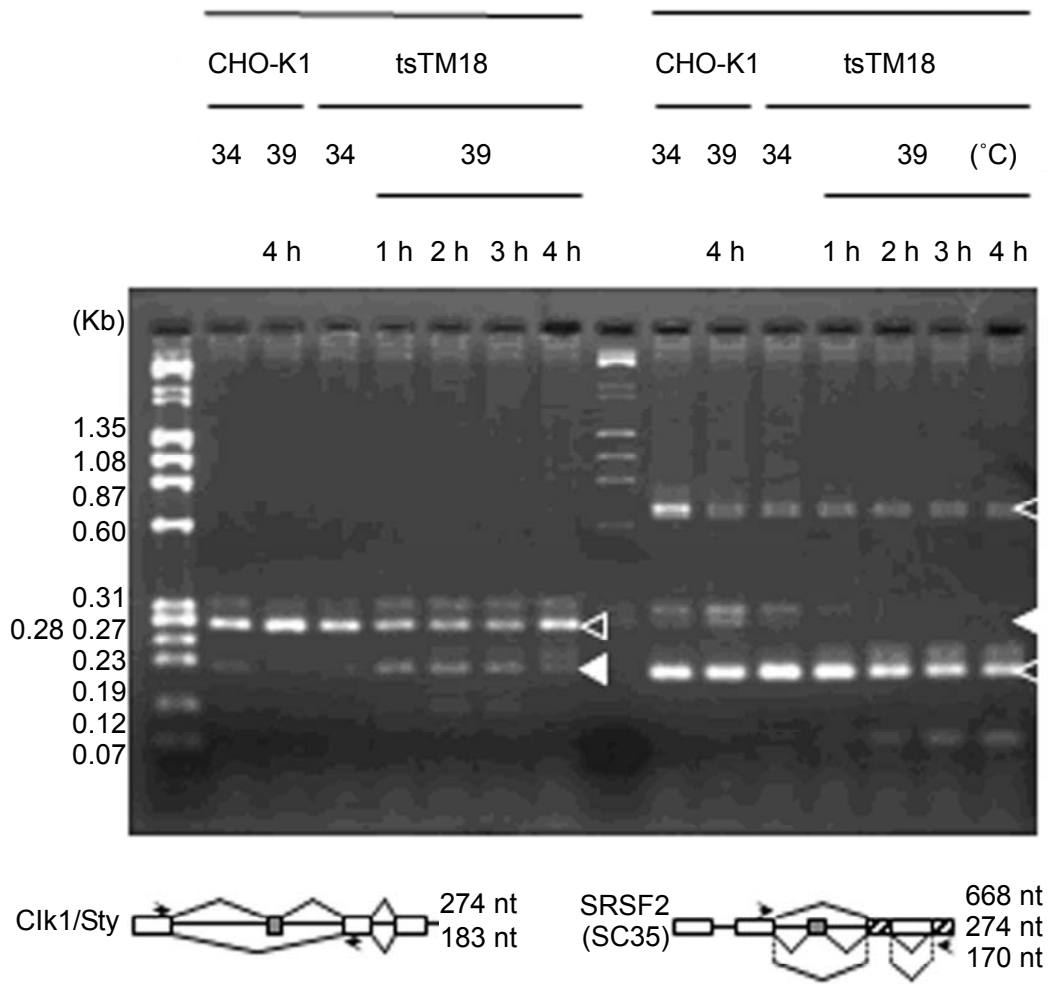

Copyright (C) 2013 SciRes. 

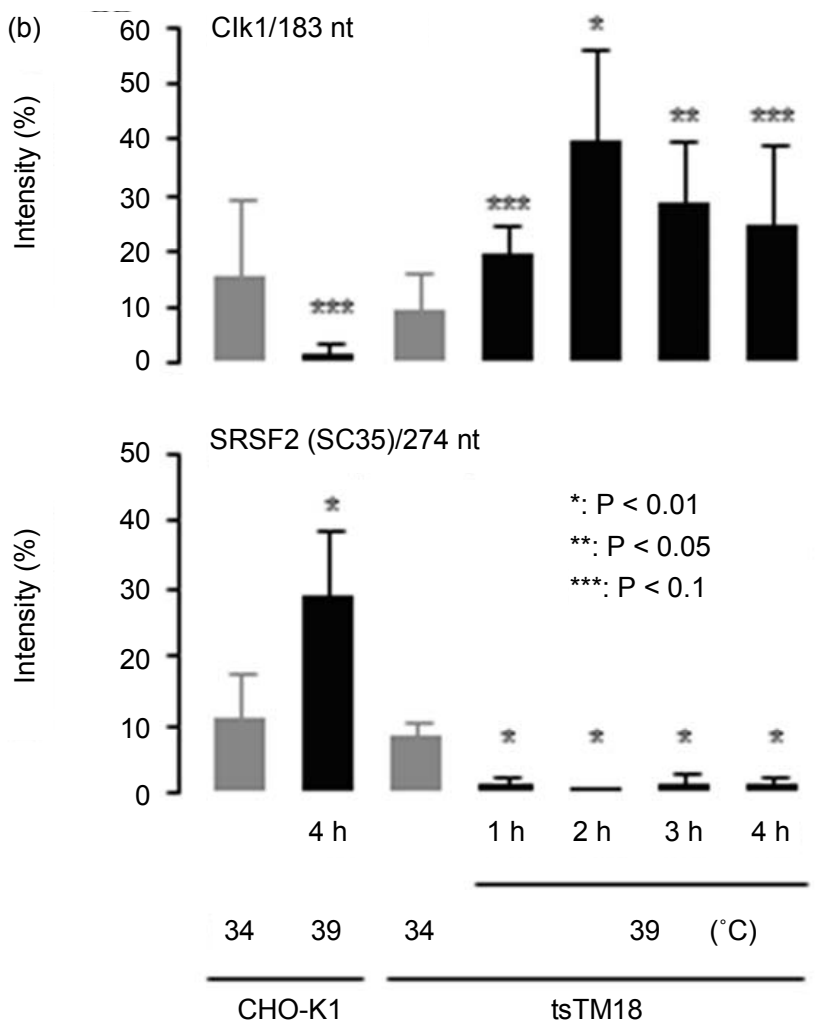

(c)

$\mathrm{Bcl}-\mathrm{X} / 702 \mathrm{nt}$

CD44/394 nt

\begin{tabular}{|c|c|c|c|c|c|}
\hline \multicolumn{2}{|c|}{$\mathrm{CHO}-\mathrm{K} 1$} & \multicolumn{4}{|c|}{ tsTM18 } \\
\hline \multirow[t]{2}{*}{34} & 39 & 34 & & & \\
\hline & $4 \mathrm{~h}$ & & $1 \mathrm{~h}$ & $2 \mathrm{~h}$ & $3 \mathrm{~h} \quad 4 \mathrm{~h}$ \\
\hline
\end{tabular}
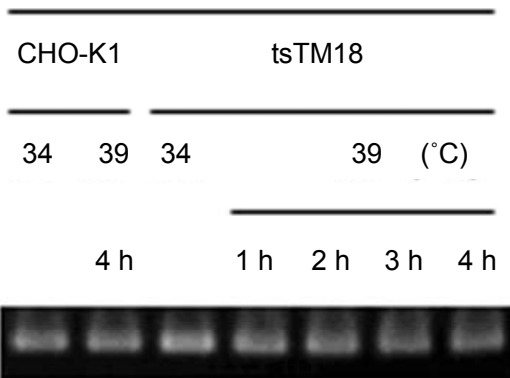

Figure 2. Temperature-sensitive (ts) defect of Smu1 affects alternative splicing. (a) RT-PCR analysis of the Clk1/Sty and SRSF2 transcripts in CHO-K1 and tsTM18 cells. Amplified regions are indicated below the photograph. Incubation times at $39^{\circ} \mathrm{C}$ are indicated above the gel. Two kinds of RT-PCR products, 274- and 183-nt, and three kinds of RT-PCR products, 668-, 274- and 170-nt, were predicted for Clk1/Sty and SRSF2, respectively. These products are present in CHO-K1 cells and in tsTM18 cells incubated at $34^{\circ} \mathrm{C}$. However, during culture of tsTM18 at $39^{\circ} \mathrm{C}$, the amount of the 183-nt product of Clk1/Sty increased, and the amount of the 274-nt product of $S R S F 2$ decreased and then disappeared, and a band around $0.1 \mathrm{~kb}$ appeared in both of the Clk1/Sty and SRSF2. (b) Quantitative analyses of the amounts of RT-PCR products in CHO-K1 and tsTM18 cells. PCR products showing significant change after incubation at $39^{\circ} \mathrm{C}$ in tsTM18 cells were analyzed. Band intensity of all isoforms in each lane, such as those shown in the panel (a), were measured and expressed as the percent intensity of the bands in each lane with standard deviation of at least five experiments. $P$ values were calculated by Student's $t$-test. In mutant cells, incubation at $39^{\circ} \mathrm{C}$ resulted in a significant increase in 183-nt product of $C l k 1$ and a significant decrease in 274-nt product of SRSF2. The ts defect of Smu1 takes affects rapidly, within 1 hour, in alternative splicing of Clk1/Sty and $S R S F 2$. (c) RT-PCR analysis of the $B c l-X$ and $C D 44$ transcripts in CHO-K1 and tsTM18 cells. In $\mathrm{CHO}-\mathrm{K} 1$ and tsTM18 cells incubated at $39^{\circ} \mathrm{C}$, there were no changes in expression of $\mathrm{Bcl}-\mathrm{X}$ and $\mathrm{CD} 44$ in the amplified region. 
cumulation of immature pre-mRNA led to the formation of enlarged speckles with proteins involved in the EJC because an accumulation of splice variants caused by alternative splicing and intron retention was found in tsTM18 cells at $39^{\circ} \mathrm{C}$ [14]. However, we have no clear evidence showing a relation between EJC proteins and immature mRNA. The effect of ts defects of Smu1 on the localization of other EJC constituents is not still clear. It is also possible that the loss of nonsense-mediated mRNA decay may cause the accumulation of splicing variants in tsTM18 cells at the nonpermissive temperature. Thus, further analysis is needed to clarify the properties of EJC proteins in tsTM18 cells at $39^{\circ} \mathrm{C}$.

For SRSF2, the relation between its phosphorylation state and the change in speckles is considerable. The antibody used in this study recognizes a phosphorylated epitope within the SR domain of SRSF2 [15]. The phosphorylation of SR proteins affects their protein-protein and protein-RNA interaction [28], intracellular localization and trafficking [29-33], and protein stability [23]. Mammalian Clk family kinases are demonstrated to phosphorylate SR proteins in vitro and SRSF1 in vivo. RTPCR analysis of Clk1/Sty showed an accumulation of the truncated form lacking kinase activity in tsTM18 cells incubated at $39^{\circ} \mathrm{C}$ (Figure 2), suggesting that the mechanism of enlargement of speckles may be mediated by the phosphorylation of SR proteins. In addition, because phosphorylation is required for their recruitment from speckle to transcription site [30], the accumulation of kinasenegative Clk1/StyT may be expected to lead to pronounced changes in alternative splicing. This is consistent with our finding of a ts defect in splicing of the unc52/perlecan [14], Clk1/Sty, and SRSF2 genes (Figure 2). Judging from our findings, in which ts defects of Smu1 in splicing were found in only several genes in tsTM18 cells, ts defects of Smu1 appeared to be restricted in splicing regulated by a few splicing factors. We conclude that ts defects of Smu1 gives rise to an accumulation of kinase-negative Clk1/Sty and may lead to alteration of the localization of factors related to splicing resulting in the enlargement of speckles. However, we have no clear evidence showing reduced kinase activity of Clk1/Sty in tsTM18 cells at $39^{\circ} \mathrm{C}$. Thus, further analysis is needed to clarify altered phosphorylation of SR proteins in a Smu1-dependent manner.

\section{ACKNOWLEDGEMENTS}

This work was supported by a Grant-in-Aid from the Ministry of Education, Culture, Sport, Science and Technology of Japan (No. 235 70012).

\section{REFERENCES}

[1] Fu, X.D. (1995) The superfamily of arginine/serine-rich splicing factors. $R N A, \mathbf{1}, 663-680$.

[2] Manley, J.L. and Tacke, R. (1996) SR proteins and splicing control. Genes and Development, 10, 1569-1579. doi:10.1101/gad.10.13.1569

[3] Graveley, B.R. (2000) Sorting out the complexity of SR protein functions. $R N A, \mathbf{6}, 1197-1211$. doi:10.1017/S1355838200000960

[4] Le Hir, H., Izaurralde, E., Maquat, L.E. and Moore, M.J. (2000) The spliceosome deposits multiple proteins 20-24 nucleotides upstream of mRNA exon-exon junctions. EMBO Journal, 19, 6860-6869. doi:10.1093/emboj/19.24.6860

[5] Le Hir, H., Moore, M.J. and Maquat, L.E. (2000) PremRNA splicing alters mRNP composition: Evidence for stable association of proteins at exon-exon junctions. $\mathrm{Ge}$ nes and Development, 14, 1098-1108. doi:10.1101/gad.14.9.1098

[6] Lamond, A.I. and Spector, D.L. (2003) Nuclear speckles: A model for nuclear organelles. Nature Reviews Molecular Cell Biology, 4, 605-612. doi:10.1038/nrm1172

[7] Tsuji, H., Matsudo, Y., Tsuji, S., Hanaoka, F., Hyodo, M. and Hori, T. (1990) Isolation of temperature-sensitive CHO-K1 cell mutants exhibiting chromosomal instability and reduced DNA synthesis at nonpermissive temperature. Somatic Cell and Molecular Genetics, 16, 461-476. doi:10.1007/BF01233196

[8] Sugaya, K., Hongo, E. and Tsuji, H. (2005) A temperature-sensitive mutation in the WD repeat-containing protein Smu1 is related to maintenance of chromosome integrity. Experimental Cell Research, 306, 242-251. doi:10.1016/j.yexcr.2005.02.017

[9] Sugaya, K., Ishihara, Y. and Sugaya, K. (2011) Enlargement of speckles of SF2/ASF due to loss of function of Smu1 is characterized in the mammalian temperaturesensitive mutant. RNA Biology, 8, 488-495. doi:10.4161/rna.8.3.14656

[10] Ge, H. and Manley, J.L. (1990) A protein factor, ASF, controls cell-specific alternative splicing of SV40 early pre-mRNA in vitro. Cell, 62, 25-34. doi:10.1016/0092-8674(90)90236-8

[11] Krainer, A.R., Conway, G.C. and Kozak, D. (1990) The essential pre-mRNA splicing factor SF2 influences 5, splice site selection by activating proximal sites. Cell, 62, 35-42. doi:10.1016/0092-8674(90)90237-9

[12] Li, X. and Manley, J.L. (2005) Inactivation of the SR protein splicing factor ASF/SF2 results in genomic instability. Cell, 122, 365-378. doi:10.1016/j.cell.2005.06.008

[13] Hongo, E., Ishihara, Y., Sugaya, K. and Sugaya, K. (2008) Characterization of cells expressing RNA polymerase II tagged with green fluorescent protein: Effect of ionizing irradiation on RNA synthesis. International Journal of Radiation Biology, 84, 778-787. doi:10.1080/09553000802345936

[14] Sugaya, K., Hongo, E., Ishihara, Y. and Tsuji, H. (2006) The conserved role of Smu1 in splicing is characterized in its mammalian temperature-sensitive mutant. Journal of Cell Science, 119, 4944-4951. doi:10.1242/jcs.03288

[15] Fu, X.D. and Maniatis, T. (1990) Factor required for mam- 
malian spliceosome assembly is localized to discrete regions in the nucleus. Nature, 343, 437-441. doi:10.1038/343437a0

[16] Ballut, L., Marchadier, B., Baguet, A., Tomasetto, C., Seraphin, B. and Le Hir, H. (2005) The exon junction core complex is locked onto RNA by inhibition of eIF4AIII ATPase activity. Nature Structural \& Molecular Biology, 12, 861-869. doi:10.1038/nsmb990

[17] Tange, T.O., Shibuya, T., Jurica, M.S. and Moore, M.J. (2005) Biochemical analysis of the EJC reveals two new factors and a stable tetrameric protein core. $R N A, \mathbf{1 1}$, 1869-1883. doi:10.1261/rna.2155905

[18] Le Hir, H. and Andersen, G.R. (2008) Structural insights into the exon junction complex. Current Opinion in Structural Biology, 18, 112-119. doi:10.1016/j.sbi.2007.11.002

[19] Duncan, P.I., Stojdl, D.F., Marius, R.M. and Bell, J.C. (1997) In Vivo regulation of alternative pre-mRNA splicing by the Clk1 protein kinase. Molecular and Cellular Biology, 17, 5996-6001.

[20] Colwill, K., Pawson, T., Andrews, B., Prasad, J., Manley, J.L., Bell, J.C. and Duncan, P.I. (1996) The Clk/Sty protein kinase phosphorylates SR splicing factors and regulates their intranuclear distribution. EMBO Journal, 15, 265-275.

[21] Nayler, O., Stamm, S. and Ullrich, A. (1997) Characterization and comparison of four serine- and arginine-rich (SR) protein kinases. Biochemical Journal, 326, 693-700.

[22] Caceres, J.F., Screaton, G.R. and Krainer, A.R. (1998) A specific subset of SR proteins shuttles continuously between the nucleus and the cytoplasm. Genes and Development, 12, 55-66. doi:10.1101/gad.12.1.55

[23] Lai, M.C., Lin, R.I. and Tarn, W.Y. (2003) Differential effects of hyperphosphorylation on splicing factor SRp55. Biochemical Journal, 371, 937-945. doi:10.1042/BJ20021827

[24] Pilch, B., Allemand, E., Facompre, M., Bailly, C., Riou, J.F., Soret, J. and Tazi, J. (2001) Specific Inhibition of Serine- and Arginine-rich Splicing Factors Phosphorylation, Spliceosome Assembly, and Splicing by the Antitumor Drug NB-506. Cancer Research, 61, 6876-6884.

[25] Soret, J., Gabut, M., Dupon, C., Kohlhagen, G., Stevenin,
J., Pommier, Y. and Tazi, J. (2003) Altered Serine/Arginine-Rich Protein Phosphorylation and Exonic Enhancer-Dependent Splicing in Mammalian Cells Lacking Topoisomerase I. Cancer Research, 63, 8203-8211.

[26] Sureau, A., Gattoni, R., Dooghe, Y., Stevenin, J. and Soret, J. (2001) SC35 autoregulates its expression by promoting splicing events that destabilize its mRNAs. EMBO Journal, 20, 1785-1796. doi:10.1093/emboj/20.7.1785

[27] Schmidt, U., Im, K.B., Benzing, C., Janjetovic, S., Rippe, K., Lichter, P. and Wachsmuth, M. (2009) Assembly and mobility of exon-exon junction complexes in living cells. $R N A$, 15, 862-876. doi:10.1261/rna.1387009

[28] Xiao, S.H. and Manley, J.L. (1997) Phosphorylation of the ASF/SF2 RS domain affects both protein-protein and protein-RNA interactions and is necessary for splicing. Genes and Development, 11, 334-344. doi:10.1101/gad.11.3.334

[29] Caceres, J.F., Misteli, T., Screaton, G.R., Spector, D.L. and Krainer, A.R. (1997) Role of the modular domains of SR proteins in subnuclear localization and alternative splicing specificity. Journal of Cell Biology, 138, 225238. doi:10.1083/jcb.138.2.225

[30] Misteli, T., Cáceres, J.F., Clement, J.Q., Krainer, A.R., Wilkinson, M.F. and Spector, D.L. (1998) Serine phosphorylation of SR proteins is required for their recruitment to sites of transcription in vivo. Journal of Cell Biology, 143, 297-307. doi:10.1083/jcb.143.2.297

[31] Lai, M.C., Lin, R.I., Huang, S.Y., Tsai, C.W. and Tarn, W.Y. (2000) A human importin- $\beta$ family protein, transportin-SR2, interacts with the phosphorylated RS domain of SR proteins. Journal of Biological Chemistry, 275, 7950-7957. doi:10.1074/jbc.275.11.7950

[32] Lai, M.C., Lin, R.I. and Tarn, W.Y. (2001) TransportinSR2 mediates nuclear import of phosphorylated SR proteins. Proceedings of the National Academy of Sciences of the United States of America, 98, 10154-10159. doi:10.1073/pnas.181354098

[33] Lin, S., Xiao, R., Sun, P., Xu, X. and Fu, X.D. (2005) Dephosphorylation-dependent sorting of SR splicing factors during mRNP maturation. Molecular Cell, 20, 413425. doi:10.1016/j.molcel.2005.09.015 